(c) 2020 Universidad Nacional Autónoma de México, Facultad de Estudios Superiores Zaragoza.

Este es un artículo Open Access bajo la licencia CC BY-NC-ND (http://creativecommons.org/licenses/by-nc-nd/4.0/).

TIP Revista Especializada en Ciencias Químico-Biológicas, 23: 1-15, 2020.

https://doi.org/10.22201/fesz.23958723e.2020.0.279

\title{
Recubrimientos para heridas con Aloe-gel combinado con alginato, pectina y quitosano: aplicaciones in vivo
}

\author{
1*Marco Antonio López-Mata, ${ }^{1}$ Ramón Gertrudis Valdez-Melchor, \\ ${ }^{2}$ Luis Quihui-Cota y ${ }^{3}$ Pablo Sergio Osuna-Amarillas \\ ${ }^{1}$ Universidad de Sonora, Departamento de Ciencias de la Salud, Blvd. Bordo Nuevo s/n, \\ Antiguo Providencia, Cd. Obregón 85040, Sonora, México. ${ }^{2}$ Centro de Investigación \\ en Alimentación y Desarrollo, A. C., Departamento de Nutrición Pública y Salud, \\ Coordinación de Nutrición, Hermosillo, 83304, Sonora, México. ${ }^{3}$ Universidad Estatal \\ de Sonora, Unidad Académica Navojoa, Navojoa 85875, Sonora, México. \\ E-mail: *marco.lopezmata@unison.mx
}

\begin{abstract}
RESUMEN
La recuperación de las heridas en la piel es un proceso complejo e interrelacionado que se desarrolla a través de varias fases (hemostasia, inflamatoria, proliferativa y remodelación). El Aloe-gel (AG) ha sido considerado un biomaterial que puede coadyuvar en la modulación, regeneración y aceleración de la recuperación del tejido celular dañado e incluso se ha recomendado para su aplicación en heridas o quemaduras superficiales de tipo cutáneas. Debido a lo anterior, se ha promovido el uso del AG como un importante biomaterial que puede ser utilizado en la fabricación de recubrimientos para heridas $(\mathrm{RH})$. Sin embargo, su aplicación directa sobre las heridas presenta desventajas, ya que puede inducir a deshidratación en la zona, rápida oxidación de sus fitoconstituyentes y baja proporción de solutos. Una estrategia que puede ayudar a conservar su actividad biológica y a sus componentes inalterados y funcionales, es su incorporación hacia matrices de polisacáridos como el alginato, pectina y quitosano. Aunque existen ya algunos biomateriales de esta mezcla que se han propuestos como RH, su aplicación en modelos in vivo es aún limitado. Por lo anterior, la presente revisión pretende documentar el desarrollo de RH con AG incorporado en polisacáridos y sus efectos en la recuperación de heridas in vivo.

Palabras clave: Aloe-gel, pectina, quitosano, recubrimiento para heridas.
\end{abstract}

Covering for wounds with Aloe-gel combined with alginate, pectin and chitosan: its applications in vivo

\begin{abstract}
Skin wound healing is a complex process that involves different interrelated phases (hemostasis, inflammation, proliferation and remodeling). Aloe-gel (AG) has been considered as a biomaterial that contributes to the modulation, regeneration and acceleration in damaged tissue, during the regeneration process; it is also recommended for burn and superficial skin wounds treatments. AG also has been considered as an important biomaterial for the elaboration of wound healing dressing. However, the direct application of AG on wounds has showed some disadvantages such as: dehydration, rapid oxidation in phytoconstituent and low proportion of solutes. The AG incorporation into polysaccharides matrix (alginate, pectin and chitosan) is a strategy used to keep the biological activity and functional compounds. Even though, there are some biomaterials that have been elaborated with these polysaccharides mixtures as proposal for wound healing dressing, their applications in animal models have been limited. Therefore, this review has as aim to document the development of wound healing dressings with AG, incorporated in polysaccharides matrix, and its effect on the wounds healing.
\end{abstract}

Keywords: Aloe-gel, pectin, chitosan, covering for wounds.

Artículo recibido el 19 de mayo del 2020.

Artículo aceptado el 08 de diciembre del 2020. 


\section{INTRODUCCIÓN}

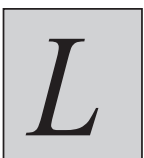

a piel es una barrera de protección contra los factores ambientales y es considerada el órgano externo más largo y expuesto del cuerpo humano.

Por lo tanto, es común que esta barrera pierda su integridad y su función anatómica normal (herida) debido a rotura, desgarro o defecto antinatural de la piel como resultado de un daño físico, químico o derivado de alguna enfermedad (Boateng, Matthews, Stevens \& Eccleston, 2008; Mir et al., 2018). Generalmente, la piel dañada puede volver a regenerar el tejido mediante un proceso de restauración que involucra la migración y colonización celular, organización del colágeno, acciones de citocinas, depósito de matriz extracelular y remodelación de la cicatriz.

Sin embargo, en algunos casos la capacidad regenerativa de la piel está comprometida o suspendida, provocando que la herida se vuelva crónica (Shah et al., 2019). Como apoyo terapéutico en la recuperación de las heridas, es común que se utilicen recubrimientos para heridas $(\mathrm{RH})$, los cuales son considerados dispositivos que protegen a la herida del ambiente externo (parcialmente) y de patógenos infecciosos durante el proceso de recuperación. Además, debe crear un ambiente óptimo que apoye en la modulación de los mecanismos celulares, químicos e inmunológicos en el interior de la herida (Moura, Dias, Carvalho \& Sousa, 2013).

A través de los años se ha incrementado considerablemente la gama de RH (vendajes, andamios, esponjas, apósitos, hidrogeles y cremas), acompañados siempre de un perfeccionamiento continuo, debido a que ningún $\mathrm{RH}$ es efectivo para tratar todos los tipos de heridas (agudas, crónicas, supurativas, exudativas y secas) (Boateng et al., 2008). Por ello, existe la perpetua búsqueda por encontrar el RH ideal, que tenga la capacidad de reproducir las propiedades naturales de la piel. Inicialmente se consideró que los polímeros sintéticos podrían ser una solución importante en la mejora de los RH. Pero actualmente se sabe, que este tipo de RH suelen acompañarse de impurezas asociadas a efectos tóxicos, reacciones inflamatorias e inmunológicas que afectan la recuperación de las heridas (Park, Lih, Park, Joung \& Han, 2017). Aun así, su uso continua vigente y parece estar apoyado por el argumento de acelerar la recuperación de las heridas, que no se observa con el uso de RH naturales (Jouybar et al., 2017).

Se ha comenzado a generar evidencia de que algunos de los nuevos RH a base de Aloe-gel (AG), han presentado mejores resultados en la recuperación de heridas, comparado con los productos de $\mathrm{RH}$ sintéticos cuando han sido utilizados en modelos animales (Jouybar et al., 2017). ElAG, es un mucílago que se extrae de la planta de Aloe vera y es considerado un importante biomaterial recomendado para tratar heridas o quemaduras superficiales, debido a sus propiedades cicatrizantes, antiinflamatorias, estimulantes del sistema inmune y antimicrobianas (de Oliveira et al., 2018; Hashemi, Madani \& Abediankenari, 2015; Maan et al., 2018). Estas propiedades bioactivas son aprovechadas para acompañar a otros biopolímeros a base de polisacáridos, con relevantes propiedades formadoras de redes poliméricas que funcionan en el RH como soporte, transporte, protector y suministrador de los componentes de AG in situ de la herida. Algunos de los principales polisacáridos que han sido considerados con estas características son: el quitosano, alginato y pectina.

En la presente revisión, mencionamos los avances alcanzados específicamente en el desarrollo de RH que han sido elaborados con base en la incorporación del AG en polisacáridos como el quitosano, alginato y pectina, así como la combinación de otros polímeros o compuestos bioactivos, con el fin de acelerar y mejorar el proceso de la recuperación de heridas in vivo. En el presente estudio, se excluyeron todos los artículos que tratan sobre el uso de polisacáridos aislados de la corteza de la hoja o de la hoja completa de Aloe vera, incluyendo a aquellos estudios con modelos celulares animal o humano (in vitro). El criterio de inclusión para esta revisión se basó en la selección de la información actualizada, relacionada con la recuperación de heridas inducidas o adquiridas en animales y/o en humanos. Por lo anterior, los objetivos versaron en documentar dos aspectos concatenados: El primero está relacionado con su naturaleza, obtención, composición, actividad biológica, aplicaciones directas sobre heridas y la limitación estructural del Aloe-gel. El segundo con los efectos en la recuperación de heridas in vivo de $\mathrm{RH}$ elaborados mediante la incorporación de AG en tres tipos de matriz: quitosano, alginato o pectina.

\section{Aloe vera}

La planta de Aloe ha sido descrita con varios nombres científicos: Aloe vera (Linneo), Aloe vulgaris (Lamarck) y Aloe barbadensis (Miller), pero en la actualidad, el nombre más utilizado es Aloe vera (A. vera) (Schweizer, 1995). Esta planta pertenece a la familia Asphodelaceae (Liliaceae) y se estima que el género Aloe comprende más de 500 especies distribuidas en el mundo (Grace, 2011). La parte más apreciada de la planta son sus hojas gruesas, de forma lanceoladas que están compuestas por tres partes principales: corteza exterior verde, envoltura vascular y parénquima incoloro. Esta última, suele confundirse con diferentes términos como pulpa inerte, tejido mucilaginoso, gel mucilaginoso, jalea mucilaginosa, gel inerte y tejido del parénquima de la hoja (Jing-Yuan, Tai-Xia, ZangGen \& Zheng-Hai, 2003; Maan et al., 2018); pero técnicamente en este trabajo lo referiremos como Aloe-gel (AG).

\section{COMPOSICIÓN QUÍMICA Y ACTIVIDAD BIOLÓGICA DEL AG}

El AG está compuesto por $99.5 \%$ de agua y el resto son remanentes sólidos $(0.5-1.0 \% \mathrm{p} / \mathrm{v})$ que incluyen compuestos hidrosolubles y liposolubles, vitaminas, minerales, enzimas, 
ácidos orgánicos, compuestos fenólicos (antraquinonas) y polisacáridos (Hamman, 2008a; Surjushe, Vasani \& Saple, 2008). Los polisacáridos junto con las antraquinonas son los componentes mayoritarios y representan hasta el $20 \%$ del peso de los sólidos totales presentes en la hoja (Zapata et al., 2013). Se ha establecido, que las células del parénquima de la planta tienen predominantemente polisacáridos, porque contienen un importante almacén de glucomanano que puede estar acetilado, parcialmente acetilado y no acetilado (Campestrini, Silveira, Duarte, Koop \& Noseda, 2013). Otros polisacáridos como la celulosa, polisacáridos pépticos, arabinana, arabinoramnosagalactana, galactana y el ácido glucorónico, también pueden encontrase como constituyentes de la planta (Chow, Williamson, Yates \& Goux, 2005; Vega, Ampuero, Díaz \& Lemus, 2005). Actualmente existe discrepancia en la composición de los polisacáridos del AG, debido a que puede variar de acuerdo con la región geográfica de la planta, estación del año, estado de desarrollo y del método de extracción para el análisis de componentes (Ray \& Aswatha, 2013).

Desde la antigüedad, las propiedades curativas del Aloe eran bien conocidas e incluso se considera que los sumerios fueron los primeros en aludir las propiedades terapéuticas de esta planta. Otra de las culturas que hizo referencia a las propiedades del Aloe fue la egipcia, debido a que se encontró dibujada la planta en vasos que datan de hasta 3 milenios (Vinson, Al Kharrat \& Andreoli, 2005). En el continente americano, el interés comercial por las hojas de Aloe es relativamente reciente, ya que este se inició en 1930 en Estados Unidos de América lo que generó una expansión tecnológica de los productos que se desarrollaron y de los procesos para conservar la vida útil de los tejidos de la planta de Aloe. Aparte del entorno comercial, se han seguido estudiando los componentes del AG y actualmente, se han encontrado diversas estructuras moleculares con propiedades cicatrizantes, antiinflamatorias, estimulantes del sistema inmune, antitumoral, antioxidante y antimicrobiana (de Oliveira et al., 2018; Hashemi et al., 2015; Maan et al., 2018).

Aunque son muy diversas las propiedades curativas, su uso se ha recomendado principalmente para heridas o quemaduras superficiales de tipo cutáneas. La actividad farmacológica del AG no puede ser atribuida a un solo compuesto en específico, ya que en el proceso de recuperación pueden estar involucrados los glucomananos, $\beta$-sitoesterol, vitaminas E y C, además de complejos enzimáticos, que pueden actuar de manera sinérgica (Hamman, 2008a).

Se ha reconocido que al aplicar AG sobre una herida, los glucomananos y posiblemente la giberelina, pueden interactuar y estimular los receptores del factor de crecimiento de los fibroblastos, que activan a su vez la proliferación celular in situ (Mansour, Ouda, Shaker \& Abdallah, 2014).
Además, pueden favorecer la producción de colágeno sobre y transversalmente en la herida, lo que acelera el proceso de cicatrización y reduce el rastro de la herida (Boudreau \& Beland, 2006). Respecto al $\beta$-sitoesterol, se ha evidenciado que puede estimular la angiogénesis en heridas mediante la expresión genética de factores de crecimiento endotelial y de sus receptores sobre la herida (Moon et al., 1999). Otro metabolito con importancia biológica es la manosa, que puede tener actividad inmunomoduladora debido a que se ha documentado que puede estimular la acción de los macrófagos para la producción de óxido nítrico, secreción de citosinas y marcadores de superficie celular (Chow et al., 2005; Oryan, Mohammadalipour, Moshiri \& Tabandeh, 2016).

Adicionalmente, la presencia de vitamina $\mathrm{C}$ en el $\mathrm{AG}$ puede estimular también la producción de colágeno, lo cual ayuda a la aceleración de la cicatrización. Mientras que la vitamina E, glutatión peroxidasa y superóxido dismutasa actúan neutralizando los efectos inflamatorios de los radicales libres que son producidos durante el proceso de recuperación de la herida (Hajhashemi, Ghannadi \& Heidari, 2012). Los efectos antiinflamatorios del AG también se han atribuido a la presencia de la manosa acetilada (comparada con manosa-6-fosfato), la cual reduce la inflamación que es inducida vía promotores de las prostaglandinas (Reynolds \& Dweck, 1999).

Por otro lado, la propiedad antibacterial del AG contra bacterias Gram-negativas y positivas también ha sido reportada. Al parecer, esta actividad directa es atribuida principalmente a la presencia de antraquinonas y saponinas, mientras que los glucomananos han sido considerados como bactericidas indirectos por sus propiedades inmunomoduladoras que pueden estimular la fagocitosis leucocitaria provocando probablemente la eliminación de la bacteria presente en la herida (Ferro et al., 2003; Habeeb et al., 2007).

El efecto antitumoral es otra propiedad biológica que se ha atribuido al AG, debido a que contiene lecitinas y acemananos. Estos dos componentes han sido considerados como quimiopreventivos y anti-genotóxicos (Hamman, 2008b). Todas las propiedades mencionadas anteriormente, han incrementado el interés por ampliar el estudio y conocimiento del AG para futuras aplicaciones en la salud humana.

\section{APLiCACIÓn direCta del AG SOBRE LAS HERIDAS}

La mayoría de los estudios relacionados con la aplicación tópica directa del AG y la recuperación de heridas, se han realizado principalmente en modelos animales y escasamente en humanos (Akaberi, Sobhani, Javadi, Sahebkar \& Emami, 2016; Maenthaisong, Chaiyakunapruk, Niruntraporn \& Kongkaew, 2007). Si bien es cierto, que el modelo animal proporciona información importante sobre el comportamiento de los factores internos y externos que intervienen en la 
recuperación de las heridas, también posee un sistema de cicatrización cutáneo diferente al humano. Los roedores tienen gran elasticidad en su piel y falta de adherencia a las estructuras subyacentes (denominada "piel suelta"), lo que permite que el proceso de recuperación de la herida se desarrolle principalmente por contracción (Kim, Mustoe \& Clark, 2015). Además, tienen una mayor densidad de folículos pilosos que apoyan en la re-epitelización de la herida. Estas diferencias, hacen difícil extrapolar los resultados experimentales y por ésto los ensayos clínicos en humanos siempre serán necesarios por su aspecto traslacional (GarciaOrue et al., 2017).

Basados en la existencia de evidencia clínica en humanos, Burusapat, Supawan, Pruksapong, Pitiseree \& Suwantemee, 2018, revisaron las publicaciones asociados con ensayos doble ciego, aleatorizados y controlados, sobre la aplicación tópica del AG y sus efectos en la aceleración de la recuperación de heridas de grosor parcial $(0.20-0.40 \mathrm{~mm})$ cubiertas con injertos de piel donada. En doce pacientes con 24 sitios donantes que fueron seleccionados como casos clínicos y tratados con AG, se observó que sus tiempos de epitelización fueron menores $(\approx$ 2 días) a los del grupo placebo $(p<0.05)$, pero las diferencias visuales no pudieron ser apreciadas. Adicionalmente, tres estudios demostraron una mejor epitelización sin demostrar cambios significativos en la mejora del dolor.

Chini et al., (2017), al consultar 178 publicaciones brasileñas que contenían datos de pacientes con heridas de cesárea, episiotomía, quemaduras, injertos de donantes, pos-hemorroidectomía y anales crónicas, encontraron que la aplicación del AG podía promover la cicatrización y disminución del dolor. Sin embargo, de la revisión de estos estudios los autores concluyeron que la evidencia de su eficacia, no era lo suficientemente significativa como para legitimar su uso sobre heridas. Por el contrario, entre algunas de las desventajas de la aplicación tópica directa del AG, se relacionan con su naturaleza deshidratante sobre la piel humana cuando fue aplicado durante $\approx 6$ días (Fox et al., 2014), y a su baja proporción de solutos con actividad biológica, que podrían limitar su actividad (Hamman, 2008b).

La baja proporción de solutos en el AG nativo, ha motivado su obtención a través de la remoción de agua para conseguir un concentrado en forma de polvo, aunque existen problemas con este proceso: el primero está relacionado con la metodología de obtención, que suele ser tediosa, de tiempo prolongado y costosa, contrario a lo que la industria requiere (Kiran \& Rao, 2014). El segundo problema, es encontrar las condiciones adecuadas de hidratación del polvo para reconstituir el hidrogel con las características similares al AG nativo. Tercero, los procesos de deshidratación del AG podrían destruir importantes fitoconstituyentes moleculares, por lo que la falta de alguno de ellos podría limitar la acción sinérgica de los mismos durante la recuperación de las heridas (Jia, Zhao, \& Jia, 2008).

Por lo anterior, la gran mayoría de los estudios prefieren usar AG de manera nativa y con el mínimo proceso posible de manipulación (optimización de costos y cuidado de fitoconstituyentes), aunque recientemente se ha progresado en la utilización de los polvos de AG con calentamiento a temperaturas bajas $\left(30{ }^{\circ} \mathrm{C}\right)$, observándose una adecuada reconstitución del gel (Kiran, Swami Hulle \& Rao, 2017), siendo éste, un camino importante de investigación vigente.

\section{LimitaCiONES DEL AG COMO MATERIAL PARA RH}

En la mayoría de los estudios, donde el AG ha sido utilizado como parte de la composición de una película o una membrana, se reportan cambios significativos en el color de las mismas (Chin, Lyn \& Hanani, 2017; Khoshgozaran-Abras, Azizi, Hamidy \& Bagheripoor-Fallah, 2012). Este cambio, ha sido atribuido a la presencia de antraquinonas, que al contacto con la luz tienden a oxidarse y provocar el cambio de color en el material, que puede variar desde un rosado a un marrón claro u oscuro (Khoshgozaran-Abras et al., 2012). Nuestro equipo de trabajo ha logrado evitar los cambios de color inducidos por AG mediante el uso de ácido cítrico como estabilizador; ejemplos de estas películas o membranas pueden consultarse en Gómez-Rodríguez et al., 2018 y López-Mata et al., 2016, 2018.

Otra limitante del AG es su baja proporción de solutos, en especial de carbohidratos. Esto limita sus propiedades filmogénicas como soporte para la elaboración de biomateriales y aplicación como RH. Esto explica porque se opta por la alternativa de combinarlo con otros biopolímeros que contengan propiedades filmogénicas adecuadas. Con esto se busca mejorar las propiedades mecánicas, sin detrimento de sus propiedades biológicas funcionales. Las combinaciones de polímeros filmogénicos con el AG han sido también una buena alternativa para incorporar compuestos bioactivos (micro y nanoencapsulados); con el objetivo de potencializar su actividad biológica y mantener los componentes funcionales (López-Mata et al., 2016).

La finalidad que se plantea con el uso de estructuras biopoliméricas radica en brindar soporte y una concentración inalterada (incluso concentrada) de los fitoconstituyentes del AG a través de la elaboración de biomateriales destinados para el RH con avances importantes en sistemas in vitro. Membranas elaboradas por entrecruzamiento de Aloe-gel/ quitosano han demostrado que el quitosano puede favorecer la estabilidad de los polisacáridos presentes en el Aloe, manteniendo su actividad biológica (Silva, Caridade, Mano \& Reis, 2013). La actividad fue observada en su capacidad de penetración en modelos de simulación de piel e incluso en diferentes estados de los procesos de recuperación. Otro 
material elaborado a base de quitosano, alginato de sodio y AG (mediante polielectrolitos complejos) ha demostrado la capacidad de atrapar componentes del AG y conservar sus funciones in vitro. Los materiales mencionados mostraron buena estabilidad, capacidad de absorción del agua, tamaños de poros que permitieron la respiración celular, la salida de humedad del ambiente y rigidez necesaria para actuar como soporte de materiales para el RH. Además, mantuvieron de manera viable fibroblastos y linfocitos humanos hasta un $90 \%$, lo que representó una citotoxicidad baja hacia estos modelos celulares. Además de estas propiedades, también se observó una migración de fibroblastos durante el proceso de cierre de la herida durante un ensayo simulado in vitro (GallardoRivera et al., 2018).

Antes de entrar al tema de las perspectivas de nuevos RH y a la aplicación de los biomateriales con AG incorporado en matriz de alginato, pectina y/o quitosano en heridas de modelos vivos, describiremos brevemente los procesos fisiopatológicos básicos relacionados con las fases de recuperación de las heridas cutáneas, para que el lector pueda tener otra visión de los factores que están involucrados en la recuperación de las heridas.

\section{Fisiopatología de la herida de la PIEL}

Las etapas de la cicatrización de una herida involucran cuatro fases que son: hemostasia, inflamatoria, proliferativa y remodelación, que pueden estar interrelacionadas o superpuestas.

Fase de hemostasia: cuando ocurre la pérdida de la integridad de la piel, el organismo responde inicialmente con una agregación plaquetaria (mediada por fibrinógeno) que se unirá a un depósito de fibrina y funcionará como un primer soporte provisional de la matriz extracelular, para formar el coágulo y detener la pérdida de sangre (VargasRuiz, 2016). Aproximadamente diez minutos después de la formación del coágulo, las plaquetas secretarán factores de crecimiento derivado de plaquetas (FCDP), factor de crecimiento transformante beta (FCT- $\beta$ ), el factor plaquetario 4 (FP4), interleucina 1(IL-1), factor angiogénico derivado de la plaqueta (FADP), factor de crecimiento endotelial vascular (FCEV), factor de crecimiento epidérmico (FCE), factor de crecimiento endotelial derivado de las plaquetas (FCEDP), factor de crecimiento celular epitelial (FCCE) y el factor de crecimiento tipo insulina (FCIL), entre otros factores. La liberación de estos factores permite el reclutamiento celular y a su vez, prepara al tejido dañado para la fase inflamatoria (Ridiandries, Tan, \& Bursill, 2018).

Fase inflamatoria: Las primeras células inflamatorias que llegan al lugar de la herida son los neutrófilos, que son atraídos por interleucina 8 (IL-8), oncogén relacionado al crecimiento $(\mathrm{GRO}-\alpha)$ y proteína inflamatoria de macrófago-2
(MIP-2) (Engelhardt et al., 1998). En el sitio de la herida y en condiciones normales (herida no infectada) los neutrófilos actuarán durante un periodo corto de tiempo $(\approx 24-48 \mathrm{~h})$ eliminando detritus celulares, partículas extrañas y bacterias (Kobayashi, 2008). La presencia prolongada de los neutrófilos y la migración descontrolada hacia el sitio de la herida, han sido asociados con un retraso en el tiempo de recuperación, debido a que los neutrófilos pueden mantener una respuesta inflamatoria excesiva por la liberación de citocinas (factor de necrosis tumoral alfa (FNT- $\alpha$ ), interleucinas $1 \beta$ y 6 ), además de una excesiva producción de especies oxígeno reactivas y proteasas que son capaces de provocar la degradación de la matriz extracelular afectando el adecuado ordenamiento del colágeno (de Oliveira, Rosowski \& Huttenlocher, 2016). Los neutrófilos también son responsables de la liberación de citocina MCP-1, MIP-1a y RANTES (Regulador de la activación, células-T normales expresadas y secretadas) que son las señales químicas de reclutamiento de los macrófagos. Esto provocará la llegada de monocitos hacia el sitio de la herida, donde serán transformados a macrófagos mediante el FCT- $\beta$ que es secretado por los gránulos alfas de las plaquetas (Barrientos, Stojadinovic, Golinko, Brem \& TomicCanic, 2008; Montón Echeverría, Pérez Redondo \& Gómez Bajo, 2007). Adicionalmente, las células endoteliales y los queratinocitos presentes en la periferia de la herida también influirán en el reclutamiento de macrófagos, mediante la secreción de quimio-atrayentes, ya que su llegada favorece la angiogénesis en la herida. En el sitio de la herida, los macrófagos cumplirán con diversas funciones de recuperación, ya que son responsables de la adecuada formación del tejido granular, apoyarán en la defensa del hospedero y eliminarán células apoptóticas. Además, secretan una serie de citocinas proinflamatorias (IL-1 y IL-6), proliferativas de fibroblastos (FCE, FCT- $\beta$ y FCDP) y de la diferenciación celular de miofibroblastos (FCT- $\beta 1$ ) que son muy necesarios en la reparación de la herida. Los macrófagos también son responsables del desarrollo de nuevos vasos sanguíneos (angiogénesis), fundamentales para el proceso de la recuperación del tejido dañado. Para estimular la angiogénesis, los macrófagos liberan factores de crecimiento, citocinas y quimiocinas, como FCDP, factor de crecimiento de fibroblastos básico (FCFb), FCEV, FNT- $\alpha$ e interferón- $\gamma$ (Hesketh, Sahin, West \& Murray, 2017). Para atender toda esta diversidad de funciones, se sabe que los macrófagos actúan mediante múltiples fenotipos que van cambiando con la evolución o la etapa de la herida. Aunque comúnmente se clasifican como macrófagos fenotipo 1 y 2 , realmente existe una heterogeneidad entre estos dos fenotipos (M1, M2a, M2b, M2c y M2d) que cumplirán su función durante las diversas etapas de la evolución de la herida (Koh \& DiPietro, 2011).

Fase proliferativa: se caracteriza por una reducción en las células inflamatorias, constante epitelización (fibroblastos y queratinocitos), angiogénesis y la formación del tejido 
granular. Para la epitelización del tejido, las células madre atraídas hacia el sitio de la herida por citocinas, se diferenciarán en células endoteliales y fibroblastos, que se multiplican en respuesta a los factores de crecimiento liberados por plaquetas y macrófagos, para iniciar la formación del tejido granular (Abkowitz, Robinson, Kale, Long \& Chen, 2003). El tejido granular se formará siguiendo un patrón de abajo hacia arriba y funcionará como una nueva matriz extracelular que resulta útil para el adecuado depósito y acomodo del colágeno tipo III. Mientras este proceso ocurre, los queratinocitos y células endoteliales presentes en el borde de la herida proliferarán y migrarán para cerrar la superficie de la herida (Ridiandries et al., 2018). Junto con la colonización celular, se dará paso continuo a la formación de nuevos vasos capilares sanguíneos que serán importantes para el suministro de oxígeno y nutrientes. A su vez, estos vasos sanguíneos facilitarán también la entrada de más fibroblastos y macrófagos. Estos últimos seguirán proporcionados factores de crecimiento que estimularán la angiogénesis y la fibroplasia en la herida (Sinno \& Prakash, 2013).

Fase de remodelación: durante esta fase se lleva a cabo la transición del tejido granular hacia la formación de la costra, y puede durar varios meses o años. En esta fase el proceso de angiogénesis y la proliferación celular se detienen y el exceso de células abandona la herida y/o sufren apoptosis (Serra et al., 2017). Los nuevos vasos sufrirán regresión, dejando en su sitio colágeno y proteínas de matriz extracelular, que serán posteriormente degradados por la acción de las metaloproteinasas de matriz extracelular (MPM) y las metaloproteinasas inhibidoras del tejido (MPIT) que son secretadas por los fibroblastos, macrófagos y neutrófilos (desJardins-Park, Foster \& Longaker, 2018; Ferranti-Ramos et al., 2017). La degradación de la matriz extracelular formada inicialmente por colágeno I, será reemplazada por la deposición del colágeno tipo III, que es más fuerte, grueso y permanente. Además, los fibroblastos serán estimulados por FCT- $\beta$ para diferenciarse a miofibroblastos y de esta forma tendrán la capacidad de producir actina del músculo liso con función contráctil. Esto favorecerá el movimiento de las células desde el borde hasta el centro de la herida para un adecuado cierre (Penn, Grobbelaar \& Rolfe, 2012). Una vez cerrada la herida el proceso de remodelación continuará durante varios meses hasta alcanzar aproximadamente el $\approx 80 \%$ de la resistencia normal de la piel (Landén, Li \& Ståhle, 2016).

\section{Perspectivas de nuevos RH}

Actualmente, la manera convencional utilizada para tratar las heridas ha sido a través de dispositivos comerciales como vendajes, esponjas, apósitos y andamios. La mayoría de las veces estos dispositivos son elaborados con materiales sintéticos de alto costo, que pueden venir acompañados de residuos o impurezas y afectar el adecuado crecimiento celular en el tejido de la herida (Sionkowska, 2011), frecuentemente asociados con reacciones inflamatorias o inmunológicas crónicas y toxicidad (Park et al., 2017). Pero su uso se encuentra aún vigente con el argumento de que los materiales sintéticos presentan mayor ventaja que las propuestas naturales (Jouybar et al., 2017).

Por lo anterior, es necesario seguir trabajando con nuevos materiales de origen natural y generar evidencia de seguridad y eficacia durante su aplicación como RH. Algunos modelos naturales con aplicaciones como RH se han basado en el desarrollo de hidrogeles, membranas, películas, andamios y esponjas. Aunque existe una gran diversidad de biomateriales, muchos no cumplen con el ideal de un RH, ya que las heridas están influenciadas por las características de éstas. Por lo tanto, el material a utilizar dependerá del tipo de herida a tratar con base en su profundidad, extensión, color y sitio anatómico en el que ocurrió. Además de la naturaleza de la herida, las propiedades del material a elegir también son un elemento importante a considerar, ya que se recomienda que el material debe mantener la humedad en la herida, absorber los exudados, incrementar la migración epidérmica, permitir una adecuada respiración, estimular la angiogénesis, protección antimicrobiana, ser no adherente a la herida y de fácil remoción, transparente, estéril, no alergénico o tóxico y con capacidad de bloquear la radiación ultravioleta solar (Borda, Macquhae \& Kirsner, 2016; Dey, Bera \& Chakrabarty, 2015; Koga, Pereira, Lipinski \& Oliveira, 2018; Tummalapalli et al., 2016). Aunado a todas estas propiedades, también se ha documentado con evidencia que la arquitectura 3D del material influye considerablemente sobre la adecuada regeneración y reparación celular, aun y cuando se trate de un mismo tipo de material (Ahmed \& Ikram, 2016; Tchemtchoua et al., 2011).

Además, se busca que los nuevos materiales para RH también ayuden a reducir el tiempo de estadio de los neutrófilos en la herida y acelerar su reemplazo por los macrófagos, Esto debido a que los primeros, por su naturaleza secretora de elastasa pueden inducir un retraso en el proceso de diferenciación y alineación de los queratinocitos en la herida y el mantenimiento de la respuesta inflamatoria, principalmente por la secreción de interleucinas proinflamatoria (Takagi et al., 2017). Se ha observado que el retiro de los neutrófilos del sitio de la herida genera reducción de la inflamación y a su vez, una mayor producción y proliferación de los fibroblastos, que incrementan la producción y secreción de colágeno, acelerando la cicatrización de la herida a través de la modificación de la estructura del colágeno (colágeno tipo III por tipo I), aumentando las conexiones de los enlaces cruzados de estos filamentos (Jouybar et al., 2017).

Por otro lado, la mayoría de los esfuerzos para demostrar la aceleración y el comportamiento de la recuperación de las 
heridas por parte de los recubrimientos biopoliméricos se han realizado principalmente en un modelo animal. Actualmente, los nuevos RH utilizados han tenido importantes avances, pero debemos continuar desarrollando nuevos biomateriales con el fin de apurar el proceso y tiempo de recuperación. Pero esto es un gran reto y no ha sido fácil, debido a que la reparación de heridas es todo un proceso que requiere de etapas dinámicas y complejas como se describe en la Figura 1 (Dhivya, Padma \& Santhini, 2015). Por lo tanto, debemos tener claro que la piel es el mejor recubrimiento que existe en la naturaleza, y en consecuencia un apósito ideal para una herida debe de intentar acercase a reproducir sus propiedades.

\section{RH-AG/Alginato}

El alginato es considerado un biopolímero natural de fácil obtención a partir de algunas algas marinas marrón (Lee \& Mooney, 2012). Químicamente es una estructura polimérica constituida por $(1,4)$-unidades- $\beta$-D-manuronato y residuos de $\alpha$-L-guluronato. Este copolímero, ha sido seleccionado como un importante biomaterial aniónico para la elaboración de $\mathrm{RH}$, debido a que se ha probado que puede mantener un ambiente húmedo y reducir las infecciones ocasionadas por bacterias (Venkatesan, Bhatnagar, Manivasagan, Kang \& Kim, 2015). Además, es biocompatible, no tóxico y tiene la capacidad de formar hidrogeles (Aderibigbe \& Buyana, 2018). Algunos modelos de películas a base de hidrogeles de alginato y AG en proporciones 95:5, 85:15 y 75:25 (v/v) han sido previamente preparadas por entrecruzamiento con cloruro de calcio al $5 \%$ (p/v) (Pereira, Carvalho, Vaz, Gil, Mendes, \& Bártolo, 2013). Pruebas in vitro realizadas sobre este modelo de películas mostraron adecuadas propiedades mecánicas para poder ser aplicadas en la piel con una solubilidad baja en agua durante 24 horas de prueba y observaron que el incremento en la absorción de agua e hinchazón en la película estaba asociado a un bajo grado de entrecruzamiento del alginato con el AG. Por lo tanto, encontraron que la absorción de agua de las películas dependía de la cantidad de AG entrecruzado y $\mathrm{pH}$, por lo que su degradación podía ser ajustada con el cambio en el contenido de AG. Estas características son útiles en sistemas de administración de fármacos, ya que permite un mayor control en la liberación de compuestos bioactivos (Pereira, Carvalho, Gil, Mendes \& Bártolo, 2013). La sumatoria de estas características de la película de alginato y $\mathrm{AG}$, ha conducido a la recomendación de utilizarla como $\mathrm{RH}$ debido a su capacidad para hidratar/deshidratar heridas con el fin de mantenerlas en un ambiente húmedo y protegidas contra infecciones, evitar su degradación por humedad y acelerar la regeneración del tejido dañado. Koga et al., 2018, dividieron 3 grupos de ratas (Wistar machos), a un grupo se le realizaron heridas dorsales de $4 \mathrm{~cm}^{2}$ para aplicar un vendaje común; al segundo se le trató con una película de alginato al $2 \%(\mathrm{p} / \mathrm{v})$ y al último con una película de alginato al $2 \%(\mathrm{p} / \mathrm{v}) /$ AG al 25\% (v/v) entrecruzado con $\mathrm{CaCl}_{2}$. El seguimiento en la recuperación de la herida fue conducido por cortes histológicos durante 3, 7, 14 y 22 días, al final observaron diferencias en la retracción de la herida con las películas de alginato que contenían AG. También se observó una buena capacidad de adherencia, liberación de fitoconstituyentes del AG, capacidad de modulación de la inflamación y angiogénesis, así como una buena colagenogénesis y disminución de la cantidad de macrófagos presentes en la herida del grupo tratado con la película de alginato/AG en

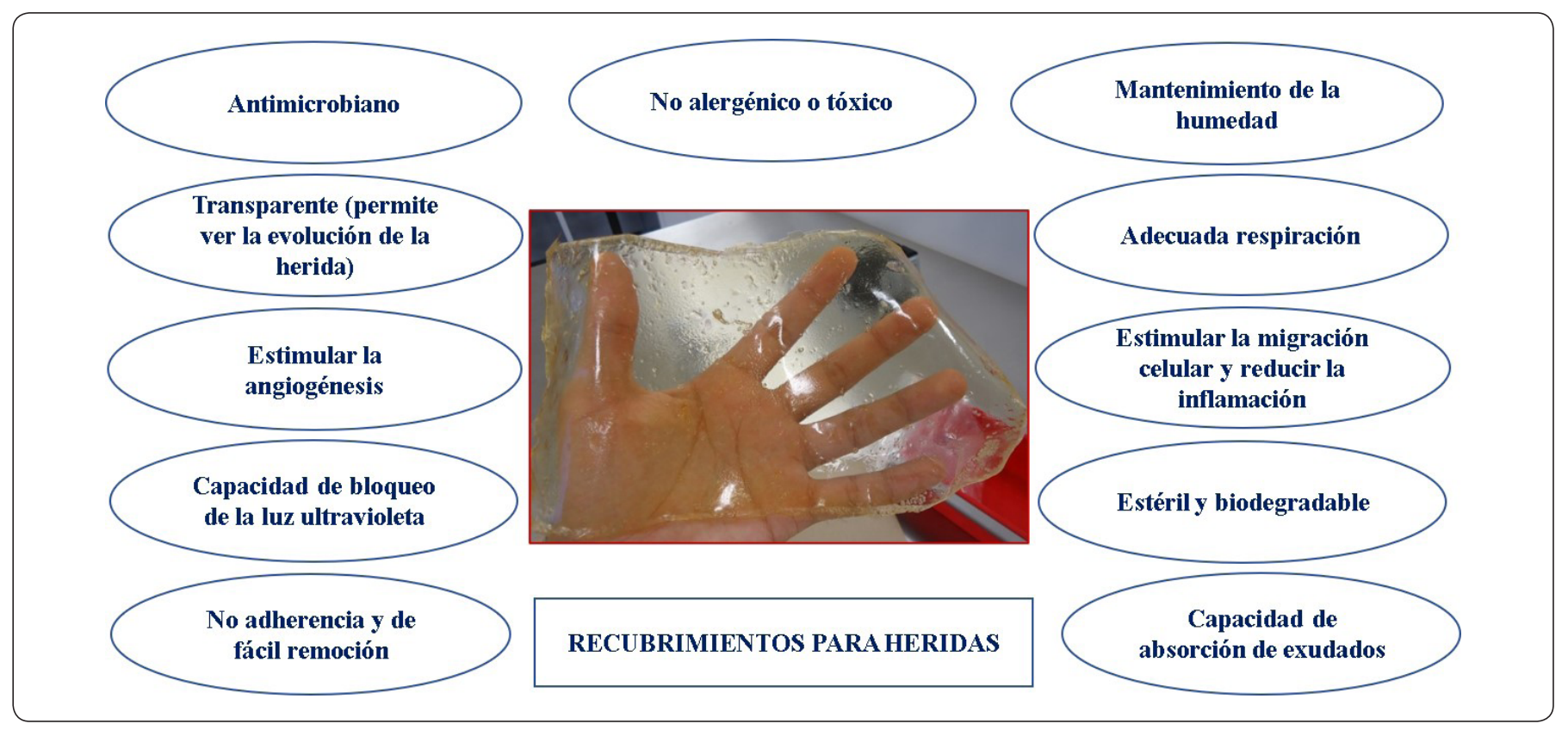

Figura 1. Características que deben de tomarse en cuenta durante la selección de un adecuado RH. Elaboración personal. 
comparación con los tratados con la película de alginato solo y el vendaje común (Koga et al., 2018).

Los estudios que han evaluado la combinación de alginato/AG como RH in vivo son muy limitados. Por lo anterior, resulta importante seguir evaluando esta combinación en forma de película y a la vez, seguir construyendo nuevos biomateriales (esponja, andamios, vendajes). Además, como científicos tenemos el deber de seguir explorando su aplicación en el modelo animal hasta llevar a los mejores candidatos a su aplicación en humanos. Por lo anterior, primero tenemos que conocer mejor los mecanismos básicos de acción del AG cuando es incorporado al alginato y sus beneficios en la recuperación de la herida.

\section{RH-AG/Pectina}

La pectina (PEC) es un heteropolisacárido conformado por al menos $65 \%$ de unidades de cadenas lineales de ácido poli- $\alpha-(1,4)$-D-galacturónico y un amplio rango de carbohidratos neutros (Voragen, Coenen, Verhoef \& Schols, 2009). Además, puede estar disponible en forma de ácidos libres, sales, ésteres metilados, acetilados y feruloilados o polisacáridos amidados. Esta diversidad molecular involucra que la PEC sea polimolecular y polidispersa, con cadenas que podrían corresponder a un peso molecular entre 50,000 y $150,000 \mathrm{Da}$ (Sriamornsak, 2003). Durante décadas, se ha reconocido que la PEC puede formar membranas (capacidad filmogénica) con adecuada compatibilidad con los sistemas biológicos e incluso es muy valorada por ser una fibra dietaria, que puede ser digerida fácilmente por la microflora en el colon, siendo los colonocitos quienes la utilizan como fuente generadora de ácidos grasos de cadena corta, para cubrir sus funciones energéticas (Lupton, 2000). Estas características han definido a la PEC como un material que podría ser colonespecífico debido a que puede encapsular, transportar y liberar fármacos en el colon y podría ser útil para tratar el cáncer de colon y algunas heridas colónicas (Auriemma et al., 2013).

En el plano de los biomateriales con potencial aplicación en la recuperación de heridas, se ha documentado que la PEC puede influir en la mejoría de las propiedades mecánicas y biológicas de los andamios electrohilados cuando es mezclada con otros biopolímeros. Andamios electrohilados de PEC-quitosano han resultado en un nuevo biomaterial con mayor resistencia, que cuando son aplicados de manera independiente, con capacidad de promover la proliferación celular, secreción de colágeno y la absorción de exudado (in vitro) (Lin, Chen, Chang \& Ni, 2013). También se ha reportado el mejoramiento de las propiedades mecánicas y biológicas de las películas AG/pectina como se ha observado en las películas de pectinaquitosano (Martins et al., 2018).

Recientemente, Gómez-Rodríguez et al., 2018, propusieron un nuevo RH a base de la combinación de pectina/AG cargada con carvacrol microencapsulado. Los estudios realizados in vitro mostraron actividad antibacterial y una adecuada permeabilidad al vapor de agua. Sin embargo, se recomienda seguir estudiando estos sistemas tanto in vitro como in vivo (Gómez-Rodríguez et al., 2018).

Por otro lado, las mezclas de PEC con otros biopolímeros también han dado por resultado la obtención de buenos modelos estructurales y con actividad mejorada sobre la recuperación de las heridas cuando el AG es adicionado. Por ejemplo la mezcla de pectina oxidada y gelatina con AG (10 $-40 \% \mathrm{p} / \mathrm{p}$ ), preparada usando una matriz de algodón que fue cubierta por sumersión en el hidrogel de pectina oxidadagelatina-AG para elaborar un apósito. Posteriormente, se usó en heridas inducidas en la piel $(8 \mathrm{~mm}$ de diámetro en porción dorsal) de ratones (cepa C57BL/6J). Conociendo que la herida de roedores cierra por retracción, la piel circundante fue suturada con apoyo de una estructura de silicón circular. Después de 8 días, se observó una curación rápida del $80 \%$, caracterizada por un fuerte efecto antiinflamatorio. Además, los exámenes histológicos revelaron una capa epidérmica delgada, formación más ordenada del colágeno y la neovascularización junto con la migración de fibroblastos y queratinocitos. Lo anterior, produjo una recuperación con baja notoriedad de la presencia de la cicatriz. En este mismo estudio, también se adicionó curcumina al apósito de pectina oxidada-gelatina-AG para mejorar su propiedad antibacterial. Se encontró que la adición de curcumina influía en el retraso de recuperación de la herida en aproximadamente $60 \%$ en un mismo tiempo de tratamiento (Tummalapalli et al., 2016). En este caso, se demostró que la adición del compuesto bioactivo con características antibacteriales, no necesariamente representa un efecto positivo en la recuperación de la herida, debido a que pueden, en ocasiones, interferir con la acción sinérgica de los fitoconstituyentes del AG e ir en detrimento de que sane.

La aceleración en la recuperación general de las heridas inducidas en ratones en el estudio antes mencionado, fueron atribuidas a la acción del acemanano. Este fitocostituyente del Aloe-gel al parecer tiene varios papeles importantes como inmunomodulador, estimulante de la migración de fibroblastos y de la síntesis de colágeno, lo que puede explicar la reducción del rastro de la cicatrización dejada por la herida.

\section{RH-AG/QUITOSANO}

El quitosano es un polisacárido conformado por unidades $\beta$-(1-4)-D-glucosamina y $\beta$-(1-4)-N-acetil-D-glucosamina, que puede obtenerse fácilmente por la desacetilación termoalcalina de la quitina (Hernández-Lauzardo, HernándezMartínez, Velázquez-del Valle, Guerra-Sánchez \& MeloGiorgana, 2007). Este copolímero policatiónico presenta grupos acetamida libres e hidroxilos en el anillo de la glucopiranosa que son susceptibles al ataque nucleofílico 
en el anillo. Esto permite realizar una amplia gama de materiales funcionales mediante la acción selectiva de grupos aminos libres (Berger et al., 2005). Además, el quitosano es considerado un biopolímero biodegradable, no tóxico, antigénico, antimicrobiano, biocompatible, hemostático y filmogénico (Miguel, Moreira \& Correia, 2019; Patrulea, Ostafe, Borchard \& Jordan, 2015). Por lo anterior, sus usos para la elaboración de biomateriales de manera independiente o combinado con otros materiales han permitido el desarrollo de diversos sistemas en forma de gel (Li et al., 2019), micro (Tan et al., 2018) o nanopartículas (Sullivan et al., 2018), membranas, (Bai et al., 2014), andamios, esponjas (Ahmed \& Ikram, 2016) y películas (Meyer et al., 2016). La mayoría de estos materiales han sido propuestos para diversas aplicaciones en el área farmacéutica, médica, cosmética y la industria alimentaria (Kumar, 2000).

En el área médica, se han propuesto algunos modelos de películas antibacteriales elaboradas a base de acetato de quitosano $(1.0 \%)$ combinadas con glicerol $(0.5 \%)$ o ácido oleico $(0.05 \%)$ que fueron aplicadas en tres pacientes humanos con tres distintos daños en la piel: (1) herida ocasionada por el retiro de un tatuaje + injerto, (2) quemadura en $1 / 3$ de la extremidad superior y (3) lesión ocasionada por fractura expuesta + injerto. Los resultados mostraron en general un adecuado grado de epitelización en las heridas y con una excelente recuperación de la piel entre los 7-10 días (Cárdenas, Anaya, von Plessing, Rojas \& Sepúlveda, 2008).

Un estudio más integral involucró el uso de un andamio nanofibrilar elaborado con electrohilado y su efecto sobre la diferenciación, proliferación, adhesión, propagación in vitro, así como, la biocompatibilidad de implantes, ensayos de recuperación y detección de anticuerpos anti-quitosano in vivo. Se observó que la forma de andamios nanofibrilares funcionaban como un buen sustrato para la adhesión, crecimiento, diferenciación e integración de la colonización celular de las tres principales células de la piel (queratinocitos, fibroblastos y células endoteliales) comparado con la forma de esponja y película (elaboradas con el mismo material), cuando se probaban durante el proceso de recuperación de las heridas inducidas en ratones (Tchemtchoua et al., 2011). Lo antes mencionado, resalta el potencial que tiene el quitosano como biomaterial para posibles usos en la recuperación de heridas, lo que ha acentuado el interés de potencializar sus propiedades mediante la combinación de otros materiales entre los que se encuentra el AG.

Los primeros indicios de la combinación de quitosano con AG para la formación de películas fueron propuestos por Khoshgozaran-Abras et al., 2012, quienes reportaron sus propiedades mecánicas, fisicoquímicas y color de las películas obtenidas, aunque realmente su finalidad era obtener un biomaterial para fines de conservación de la vida de anaquel de alimentos (Khoshgozaran-Abras et al., 2012). Posteriormente, esta combinación pasó al área química biológica con el estudio realizado por Silva et al., 2013, quienes probaron el entrecruzamiento de quitosano con $\mathrm{AG}$, utilizando genipina como un entrecruzante. El resultado fue una película con mayor rigidez y humectabilidad, logrando mantener la actividad metabolica de células similares a los fibroblastos (cepa L929). Por esos motivos, propusieron que la membrana obtenida podría tener potencial como apósito activo en la recuperación de heridas. El mismo grupo de investigación preparó membranas de quitosano/AG (de 2:1 y $1: 1, \mathrm{v} / \mathrm{p})$ y observaron buena compatibilidad con células de fibroblastos humanos (Silva, Popa, Gomes, Cerqueira, Marques, Caridade, Teixeira, Sousa, Mano \& Reis, 2013).

Otro estudio innovador es donde las micropartículas cargadas de Aloe vera /quitosano/vitamina E con o sin ácido hialurónico fueron elaboradas mediante secado por aspersión. Este RH también fue cargado con un radioisótopo technetium99m, que funcionaría como un marcador para indicar la penetración o mantenimiento de los componentes del $\mathrm{RH}$ en la herida o su migración hacía los tejidos circundantes. Estas micropartículas fueron aplicadas de manera tópica (1 $\mathrm{mg} / \mathrm{g})$ en quemaduras de segudo grado $\left(5 \mathrm{~cm}^{2}\right)$ inducidas en ratones Wistar y su evolución fue monitoreada durante 28 días. Las micropartículas mostraron una adecuada adherencia, biodistribución de los componentes, reordenamiento celular sobre la herida y una cicatrización estética, comparada con otras formulaciones probadas (Buffer con y sin ácido hialurónico) al paso de 14 días. Al final del ensayo, se encontró una reepitelización (iniciada a la 4 días y finalizada a los 28 días), los componentes no mostraron adherencia o efectos en la deformación de la herida. Por el contrario, la herida fue más estética, debido a la presecia de una red densa de colágeno, ausencia de autólisis celular y exudado con sangre y albúmina. Además, se comprobó que el radioisótopo no se distribuye hacia la sangre, lo que demostró que los componentes bioactivos se quedaban en la herida (Pereira, Santos-Oliveira, Albernaz, Canema, Weismüller, Magalhaes, Lima-Ribeiro, Pohlmann \& Guterres, 2014).

Por otro lado, Singh, Gupta \& Gupta, 2018 elaboraron bionanocompósitos (dextran/nanosoya/glicerol/quitosano) adicionados con $\mathrm{AG}$ que fueron aplicados en heridas dorsales inducidas $\left(10 \times 10 \mathrm{~mm}^{2}\right)$ en ratones albinos (cepa BALB/c). Los autores resaltaron que el principal compuesto bioactivo de los bionanocompósitos fue el Aloe vera que mostró su influecia inmunomoduladora al acelerar la cicatrización y reducir el rastro de la cicatriz, que fue mediada por la adecuada proliferación de fibroblastos y síntesis de colágeno. Lo anterior, aceleró el proceso de recuperación de la herida ( $81 \%$ en 7 días y $100 \%$ en 14 días) comparado con controles bionanocompósito con y sin miel de manuka (73\% en 7 días y 100\% en 21 días) (Singh et al., 2018). 
Recientemente, Abdel-Mohsen et al., 2020 elaboraron un $\mathrm{RH}$ basado en una fibra multifuncional (hueca) compuesta de colágeno/quitosano-glucano/Aloe vera (1/2/2 en razón de peso) (gel deshidratado). Dicho $\mathrm{RH}$ fue evaluado en la recuperación de las heridas inducidas en el dorso de ratas Wistar y las áreas de su cicatrización fueron medidas $(0$, 4 y 8 días). Los autores, reportaron una reducción de la contracción de la herida del $42 \%$ en tan solo 4 días y $92 \%$ a 8 días de iniciado el tratamiento, siendo significativamente mayor al compararse con el resultado observado con la aplicación de los elementos nativos de la fibra [colágeno, colágeno/quitosano-glucano) y gasa convencional (control)]. La presencia del Aloe vera en este RH fue asociada con una adecuada hidratación de la herida y reducción de las etapas de la hemostasia, inflamatoria, proliferativa y de remodelación del tejido durante el tiempo de recuperación. También se observó un aumento de enzimas antioxidantes en el entorno de la herida y una adecuada migración de fibroblastos (AbdelMohsen et al., 2020).

Es importante resaltar, que existen más investigaciones sobre la mezcla del AG con el quitosano e incluso los estudios muestran ventajas aparentes en la recuperación del 92\%$100 \%$ en un lapso de 8 a 14 días con respecto a otros como RH de alginato y pectina (Tabla I). Pero esto también puede ser confuso debido a la variación que existe en la dimensión de las heridas inducidas en los roedores y el tiempo de evaluación de la recuperación de éstas, aunque todos coinciden con la misma parte anatómica estudiada y el efecto positivo del AG.

\section{Conclusiones}

Existe información publicada limitada con enfoque a las aplicaciones in vivo de $\mathrm{RH}$ elaborados con base en la combinación de AG con quitosano, alginato y PEC. Es notoria la importancia que se documenta sobre las propiedades que muestran los biomateriales que contienen AG, cuando son aplicados en el modelo animal. Por otra parte, los estudios frecuentemente reiteran que los fitoconstituyentes (énfasis en acemananos) del AG pueden inducir a una reordenación del colágeno, estimulación de la neovascularización, migración celular de fibroblastos y queratinocitos. Además, reportan un menor estadio de los neutrófilos en la herida lo cual reduce el proceso inflamatorio y a su vez, favorece la cicatrización de la herida dejando un menor rastro de la presencia de ésta, con un aspecto más estético. Otra ventaja del uso del AG en los $\mathrm{RH}$ radica en que sus componentes suelen mantenerse in situ sobre la herida, sin que la distribución de los fitoconstituyentes llegue al torrente sanguíneo. Consideramos que es necesario seguir trabajando en este sentido para proponer y desarrollar nuevos RH con AG y generar evidencia adicional que muestren datos de mayor efectividad que los materiales comerciales. Es importante recordar que, si bien es cierto, que las heridas del modelo animal suelen aportar información importante del comportamiento de la mismas, su proceso de recuperación difiere significativamente a las del ser humano. Además, los experimentos donde se inducen heridas a los roedores suelen ser de dimensiones y tiempos de evaluación de recuperación distintos, por lo que son factores importantes para estandarizar. A lo anterior, se suma la dificultad que representa el AG como mezcla heterogénea de componentes (minoritarios y mayoritarios) cuya acción es difícil de monitorear durante el proceso de recuperación de las heridas. Por lo anterior, es necesario continuar con este tipo de estudios enfocados a la creación de materiales semejantes o más efectivos de los que existen comercialmente y llevar estos nuevos $\mathrm{RH}$ a su aplicación para la salud humana.

\section{REFERENCIAS}

Abdel-Mohsen, A. M., Frankova, J., Abdel-Rahman, R. M., Salem, A. A., Sahffie, N. M., Kubena, I. \& Jancar, J. (2020). Chitosan-Glucan Complex Hollow Fibers Reinforced Collagen Wound Dressing Embedded with Aloe vera. II. Multifunctional Properties to Promote Cutaneous Wound Healing. International Journal of Pharmaceutics, 119349. https://doi.org/10.1016/j.ijpharm.2020.119349

Abkowitz, J. L., Robinson, A. E., Kale, S., Long, M. W. \& Chen, J. (2003). Mobilization of hematopoietic stem cells during homeostasis and after cytokine exposure. Blood, 102(4), 1249-1253. DOI: 10.1182/blood-2003-01-0318

Aderibigbe, B. \& Buyana, B. (2018). Alginate in wound dressings. Pharmaceutics, 10(2), 42. https://doi. org/10.3390/pharmaceutics10020042

Ahmed, S. \& Ikram, S. (2016). Chitosan Based Scaffolds and Their Applications in Wound Healing. Achievements in the Life Sciences, 10(1), 27-37. https://doi.org/10.1016/j. als.2016.04.001

Akaberi, M., Sobhani, Z., Javadi, B., Sahebkar, A. \& Emami, S. A. (2016). Therapeutic effects of Aloe spp. In traditional and modern medicine: A review. Biomedicine \& Pharmacotherapy, 84, 759-772. https://doi.org/10.1016/j. biopha.2016.09.096

Auriemma, G., Mencherini, T., Russo, P., Stigliani, M., Aquino, R. P. \& Del Gaudio, P. (2013). Prilling for the development of multi-particulate colon drug delivery systems: Pectin vs. pectin-alginate beads. Carbohydrate Polymers, 92(1), 367-373. DOI: 10.1016/j.carbpol.2012.09.056

Bai, H., Zhang, H., He, Y., Liu, J., Zhang, B. \& Wang, J. (2014). Enhanced proton conduction of chitosan membrane enabled by halloysite nanotubes bearing sulfonate polyelectrolyte brushes. Journal of Membrane Science, 454, 220-232. https://doi.org/10.1016/j. memsci.2013.12.005

Barrientos, S., Stojadinovic, O., Golinko, M. S., Brem, H. \& Tomic-Canic, M. (2008). Perspective Article: Growth factors and cytokines in wound healing. Wound Repair and Regeneration, 16(5), 585-601. DOI: 10.1111/j.1524475X.2008.00410.x

Berger, J., Reist, M., Chenite, A., Felt-Baeyens, O., Mayer, J. 
Tabla I. Características de varios RH y los efectos de su aplicación en la recuperación de heridas inducidas en modelos animal reportados por la literatura.

\begin{tabular}{|c|c|c|c|c|c|c|c|}
\hline $\begin{array}{c}\text { Material del } \\
\text { recubrimiento }\end{array}$ & $\begin{array}{c}\text { Tipo de } \\
\text { dispositivo }\end{array}$ & $\begin{array}{l}\text { Modelo } \\
\text { vivo } \\
\text { utilizado }\end{array}$ & $\begin{array}{l}\text { Tipo de } \\
\text { herida }\end{array}$ & $\begin{array}{l}\text { Componente } \\
\text { del } \text { Aloe a } \\
\text { quien se le } \\
\text { atribuye la } \\
\text { propiedad de } \\
\text { recuperación } \\
\text { de la herida } \\
\end{array}$ & $\begin{array}{l}\text { Tiempo de } \\
\text { evaluación } \\
\text { de la } \\
\text { recuperación } \\
\text { de la herida }\end{array}$ & $\begin{array}{c}\text { Beneficios del } \\
\text { biomaterial durante } \\
\text { la recuperación de la } \\
\text { herida }\end{array}$ & Referencia \\
\hline $\begin{array}{l}25 \% \mathrm{AG} / 2 \% \\
\text { alginato. }\end{array}$ & Película. & $\begin{array}{l}\text { Ratas } \\
\text { macho } \\
\text { (Wistar). }\end{array}$ & $\begin{array}{l}\text { Dorsal } \\
\left(4 \mathrm{~cm}^{2}\right) .\end{array}$ & Acemanano. & $\begin{array}{l}\text { En } 22 \text { días } \\
\text { No hay } \\
\text { diferencias en } \\
\text { la retracción } \\
\text { de la herida, } \\
\text { vendaje } \\
\text { común, } \\
\text { alginato y } \\
\text { AG/alginato. }\end{array}$ & $\begin{array}{l}\text { Adherencia. } \\
\text { Liberación de } \\
\text { fitoconstituyentes. } \\
\text { Modulación de la } \\
\text { inflamación y la } \\
\text { angiogénesis. } \\
\text { Estimulación de la } \\
\text { producción de colágeno } \\
\text { (incremento del tipo I). }\end{array}$ & $\begin{array}{l}\text { Koga et al., } \\
2018\end{array}$ \\
\hline $\begin{array}{l}\text { Aloe-vera/ } \\
\text { quitosano/ } \\
\text { vitamina } \\
\text { E/ácido } \\
\text { hialurónico/ } \\
\text { radioisótopo. }\end{array}$ & $\begin{array}{l}\text { Micropartículas } \\
\text { aplicación } \\
\text { tópica }(1 \mathrm{~g} \text { de } \\
\text { formulación } \\
(1 \mathrm{mg} / \mathrm{g}) \mathrm{de} \\
\text { partículas } \\
\text { diariamente, } \\
\text { una vez al día. }\end{array}$ & $\begin{array}{l}\text { Ratones } \\
\text { Wistar. }\end{array}$ & $\begin{array}{l}\text { Quemadura } \\
\text { de segundo } \\
\text { grado en } \\
\text { dorso } \\
\left(5 \mathrm{~cm}^{2}\right) \text {. }\end{array}$ & $\begin{array}{l}\text { Aloe vera/sin } \\
\text { especificar } \\
\text { componente. }\end{array}$ & $\begin{array}{l}28 \text { días } \\
(100 \% \text { de } \\
\text { recuperación). }\end{array}$ & $\begin{array}{l}\text { Mucoadhesividad al tejido. } \\
\text { Biodistribución de sus } \\
\text { componentes. } \\
\text { Mejoras en la migración } \\
\text { de fibroblastos y } \\
\text { queratinocitos. } \\
\text { Adecuada remodelación } \\
\text { celular. } \\
\text { Colágeno mejor } \\
\text { organizado. } \\
\text { Cicatrización estética. } \\
\text { Aceleración en la } \\
\text { recuperación. } \\
\text { Estratos córneos bien } \\
\text { definidos. }\end{array}$ & $\begin{array}{l}\text { Pereira et al., } \\
2014\end{array}$ \\
\hline $\begin{array}{l}\text { Dextran/ } \\
\text { nanosoya// } \\
\text { quitosano } \\
\text { con Aloe gel } \\
\text { adicionado. }\end{array}$ & $\begin{array}{l}\text { Membrana } \\
\text { (nanobio- } \\
\text { compósito). }\end{array}$ & $\begin{array}{l}\text { Ratones } \\
\text { albinos } \\
\text { (cepa } \\
\text { BALB/c). }\end{array}$ & $\begin{array}{l}\text { Heridas } \\
\text { dorsales }(10 \\
\left.\text { x } 10 \mathrm{~mm}^{2}\right)\end{array}$ & $\begin{array}{l}\text { Aloe vera/sin } \\
\text { especificar } \\
\text { componente. }\end{array}$ & $\begin{array}{l}14 \text { días } \\
(100 \% \text { de } \\
\text { recuperación). }\end{array}$ & $\begin{array}{l}\text { Rápida cicatrización y } \\
\text { reducción del rastro de la } \\
\text { herida. } \\
\text { Prolifereación de } \\
\text { fibroblastos y una } \\
\text { adecuada sintésis de } \\
\text { colágeno. }\end{array}$ & $\begin{array}{l}\text { Singh et al., } \\
2018\end{array}$ \\
\hline $\begin{array}{l}\text { Colágeno/ } \\
\text { quitosano- } \\
\text { glucano/Aloe } \\
\text { vera. }\end{array}$ & $\begin{array}{l}\text { Fibra } \\
\text { multifuncional } \\
\text { (hueca). }\end{array}$ & $\begin{array}{l}\text { Dorso } \\
\text { de ratas } \\
\text { Wistar. }\end{array}$ & $\begin{array}{l}\text { Herida } \\
\text { dorsal } \approx \\
2 \mathrm{~cm} \text { de } \\
\text { diámetro } \\
\text { (no } \\
\text { especificada } \\
\text { por el autor. }\end{array}$ & $\begin{array}{l}\text { Aloe vera/sin } \\
\text { especificar } \\
\text { componente. }\end{array}$ & $\begin{array}{l}8 \text { días } \\
\text { (92\% de } \\
\text { recuperación), } \\
\text { aún con } \\
\text { rastros } \\
\text { visuales de } \\
\text { la herida sin } \\
\text { cerrar. }\end{array}$ & $\begin{array}{l}\text { Adecuada hidratación } \\
\text { Rápida hemostasia. } \\
\text { Reducción del proceso } \\
\text { inflamatorio, proliferativo } \\
\text { y de remodelación del } \\
\text { tejido. }\end{array}$ & $\begin{array}{l}\text { Abdel- } \\
\text { Mohsen } \\
\text { et al., } 2020\end{array}$ \\
\hline
\end{tabular}


M. \& Gurny, R. (2005). Pseudo-thermosetting chitosan hydrogels for biomedical application. International Journal of Pharmaceutics, 288(2), 197-206. https://doi. org/10.1016/j.ijpharm.2004.07.036

Boateng, J. S., Matthews, K. H., Stevens, H. N. E. \& Eccleston, G. M. (2008). Wound Healing Dressings and Drug Delivery Systems: A Review. Journal of Pharmaceutical Sciences, 97(8), 2892-2923. https://doi.org/10.1002/ jps. 21210

Borda, L. J., Macquhae, F. E. \& Kirsner, R. S. (2016). Wound Dressings: A Comprehensive Review. Current Dermatology Reports, 5(4), 287-297. DOI: 10.1007/ s13671-016-0162-5

Boudreau, M. D. \& Beland, F. A. (2006). An evaluation of the biological and toxicological properties of Aloe barbadensis (Miller), Aloe vera. Journal of Environmental Science and Health Part C, 24(1), 103-154. https://doi. org/10.1080/10590500600614303

Burusapat, C., Supawan, M., Pruksapong, C., Pitiseree, A. \& Suwantemee, C. (2018). Topical aloe vera gel for accelerated wound healing of split-thickness skin graft donor sites: A double-blind, randomized, controlled trial and systematic review. Plastic and reconstructive surgery, 142(1), 217-226. DOI: 10.1097/PRS.0000000000004515

Campestrini, L. H., Silveira, J. L. M., Duarte, M. E. R., Koop, H. S. \& Noseda, M. D. (2013). NMR and rheological study of Aloe barbadensis partially acetylated glucomannan. Carbohydrate polymers, 94(1), 511-519. https://doi. org/10.1016/j.carbpol.2013.01.020

Cárdenas, G., Anaya, P., von Plessing, C., Rojas, C. \& Sepúlveda, J. (2008). Chitosan composite films. Biomedical applications. Journal of Materials Science: Materials in Medicine, 19(6), 2397-2405. DOI: 10.1007/ s10856-007-3275-3

Chin, S. S., Lyn, F. H. \& Hanani, Z. N. (2017). Effect of Aloe vera (Aloe barbadensis Miller) gel on the physical and functional properties of fish gelatin films as active packaging. Food Packaging and shelf life, 12, 128-134. https://doi.org/10.1016/j.fpsl.2017.04.008

Chini, L. T., Mendes, R. A., Siqueira, L. R., Silva, S. P., dos Santos Silva, P. C., Dázio, E. M. R. \& Fava, S. M. C. L. (2017). El uso del Aloe sp (sábila) en heridas agudas y crónicas: Revisión integradora. Aquichan, 17(1), 7-17.

Chow, J. T.-N., Williamson, D. A., Yates, K. M. \& Goux, W. J. (2005). Chemical characterization of the immunomodulating polysaccharide of Aloe vera $\mathrm{L}$. Carbohydrate Research, 340(6), 1131-1142. https://doi. org/10.1016/j.carres.2005.02.016

de Oliveira, A. C. L., Tabrez, S., Shakil, S., Khan, M. I., Asghar, M. N., Matias, B. D., Batista, J. M. A. D. S., Rosal, M. M., de Lima, M. M. D. F., Gomes, S. R. F., de Carvalho, R. M., de Morales, G. P., de Alencar, M. V. O. B., Islam, M. T. \& Cavalcante, A. A. C. (2018). Mutagenic, antioxidant and wound healing properties of
Aloe vera. Journal of Ethnopharmacology, 227, 191-197. https://doi.org/10.1016/j.jep.2018.08.034

de Oliveira, S., Rosowski, E. E. \& Huttenlocher, A. (2016). Neutrophil migration in infection and wound repair: Going forward in reverse. Nature Reviews Immunology, 16(6), 378-391. DOI: 10.1038/nri.2016.49

desJardins-Park, H. E., Foster, D. S. \& Longaker, M. T. (2018). Fibroblasts and wound healing: An update. Regenerative Medicine, 13(5), 491-495. DOI: 10.2217/rme-2018-0073

Dey, A., Bera, R. \& Chakrabarty, D. (2015). Influence of Aloe vera on the properties of N-vinylpyrrolidoneAcrylamide copolymer hydrogel. Materials Chemistry and Physics, 168, 168-179. https://doi.org/10.1016/j. matchemphys.2015.11.017

Dhivya, S., Padma, V. V. \& Santhini, E. (2015). Wound dressings - a review. BioMedicine, 5(4), 22. DOI: 10.7603/s40681-015-0022-9

Engelhardt, E., Toksoy, A., Goebeler, M., Debus, S., Bröcker, E.-B. \& Gillitzer, R. (1998). Chemokines IL-8, GRO $\alpha$, MCP-1, IP-10, and Mig Are Sequentially and Differentially Expressed During Phase-Specific Infiltration of Leukocyte Subsets in Human Wound Healing. The American Journal of Pathology, 153(6), 1849-1860. https://doi.org/10.1016/ S0002-9440(10)65699-4

Ferranti-Ramos, A., Garza-Garza, G., Bátiz-Armenta, J., Martínez-Delgado, G., De la Garza-Álvarez, F., Martínez-Menchaca, H. R. \& Rivera-Silva, G. (2017). Metaloproteinasas de la matriz extracelular y su participación en el proceso de cicatrización. Medicas UIS, 30, 55-62. http://dx.doi.org/10.18273/revmed. v30n2-2017006

Ferro, V. A., Bradbury, F., Cameron, P., Shakir, E., Rahman, S. R. \& Stimson, W. H. (2003). In vitro susceptibilities of Shigella flexneri and Streptococcus pyogenes to inner gel of Aloe barbadensis Miller. Antimicrobial Agents and Chemotherapy, 47(3), 1137-1139. DOI: 10.1128/ AAC.47.3.1137-1139.2003

Fox, L. T., Du Plessis, J., Gerber, M., Van Zyl, S., Boneschans, B. \& Hamman, J. H. (2014). In Vivo skin hydration and anti-erythema effects of Aloe vera, Aloe ferox and Aloe marlothii gel materials after single and multiple applications. Pharmacognosy Magazine, 10(Suppl 2), S392. DOI: 10.4103/0973-1296.133291

Gallardo-Rivera, R., de los Ángeles Aguilar-Santamaría, M., Silva-Bermúdez, P., García-López, J., Tecante, A., Velasquillo, Román-Guerrero, A., Pérez-Alonso, C., Vázquez-Torres, H. \& Shirai, K. (2018). Polyelectrolyte complex of Aloe vera, chitosan, and alginate produced fibroblast and lymphocyte viabilities and migration. Carbohydrate Polymers, 192, 84-94. https://doi. org/10.1016/j.carbpol.2018.03.044

Garcia-Orue, I., Gainza, G., Gutierrez, F. B., Aguirre, J. J., Evora, C., Pedraz, J. L, Herández, R. M., Delgado, A. \& Igartua, M. (2017). Novel nanofibrous dressings 
containing rhEGF and Aloe vera for wound healing applications. Biomaterials in Tissue Engineering, 523(2), 556-566. DOI: 10.1016/j.ijpharm.2016.11.006

Gómez-Rodríguez, G. H., López-Mata, M. A., ValbuenaGregorio, E., Melchor, R. G. V., Campos-García, J. C., Silva-Beltrán, N. P., Quihui-Cota, L., Ruiz-Cruz, S. \& Juárez, J. (2018). Microencapsulation of Carvacrol Using Pectin/Aloe-gel as a Novel Wound Dressing Films. Current Topics in Medicinal Chemistry, 18(14), 12611268. DOI: $10.2174 / 1568026618666180810141455$

Grace, O. M. (2011). Current perspectives on the economic botany of the genus Aloe L. (Xanthorrhoeaceae). South African Journal of Botany, 77(4), 980-987. DOI: 10.1016/j.sajb.2011.07.002

Habeeb, F., Shakir, E., Bradbury, F., Cameron, P., Taravati, M. R., Drummond, A. J., Gray, A. I. \& Ferro, V. A. (2007). Screening methods used to determine the anti-microbial properties of Aloe vera inner gel. Methods, 42(4), 315320. https://doi.org/10.1016/j.ymeth.2007.03.004

Hajhashemi, V., Ghannadi, A. \& Heidari, A. H. (2012). Anti-inflammatory and wound healing activities of Aloe littoralis in rats. Research in Pharmaceutical Sciences, 7(2), 73.

Hamman, J. H. (2008a). Composition and Applications of Aloe vera Leaf Gel. Molecules, 13(8), 1599-1616. DOI: 10.3390/molecules 13081599

Hamman, J. H. (2008b). Composition and Applications of Aloe vera Leaf Gel. Molecules, 13(8), 1599-1616. DOI: 10.3390/molecules13081599

Hashemi, S. A., Madani, S. A. \& Abediankenari, S. (2015). The review on properties of Aloe vera in healing of cutaneous wounds. BioMed Research International, 2015, ID 714216. https://doi.org/10.1155/2015/714216

Hernández-Lauzardo, A. N., Hernández-Martínez, M., Velázquez-del Valle, M. G., Guerra-Sánchez, M. G. \& Melo-Giorgana, G. E. (2007). Actividad antifúngica del quitosano en el control de Rhizopus stolonifer (Ehrenb.: Fr.) Vuill. y Mucor spp. Revista Mexicana de Fitopatología, 25(2), 109-113.

Hesketh, M., Sahin, K. B., West, Z. E. \& Murray, R. Z. (2017). Macrophage Phenotypes Regulate Scar Formation and Chronic Wound Healing. International Journal of Molecular Sciences, 18(7), 1545. DOI: 10.3390/ ijms 18071545

Jia, Y., Zhao, G. \& Jia, J. (2008). Preliminary evaluation: The effects of Aloe ferox Miller and Aloe arborescens Miller on wound healing. Journal of Ethnopharmacology, 120(2), 181-189. https://doi.org/10.1016/j.jep.2008.08.008

Jing-Yuan, L. I., Tai-Xia, W., Zang-Gen, S. \& Zheng-Hai, H. (2003). Relationship between leaf structure and aloin content in six species of Aloe. L. L. Acta Botanica Sinica, 45, 504-600.

Jouybar, A., Seyedjafari, E., Ardeshirylajimi, A., ZandiKarimi, A., Feizi, N., Khani, M.-M. \& Pousti, I. (2017).
Enhanced skin regeneration by herbal extract-coated poly-L-lactic acid nanofibrous scaffold. Artificial Organs, 41(11), E296-E307. https://doi.org/10.1111/aor.12926

Khoshgozaran-Abras, S., Azizi, M. H., Hamidy, Z. \& Bagheripoor-Fallah, N. (2012). Mechanical, physicochemical and color properties of chitosan basedfilms as a function of Aloe vera gel incorporation. Carbohydrate Polymers, 87(3), 2058-2062.

Kim, D. J., Mustoe, T. \& Clark, R. A. (2015). Cutaneous wound healing in aging small mammals: A systematic review. Wound Repair and Regeneration, 23(3), 318-339. DOI: $10.1111 /$ wrr. 12290

Kiran, P. \& Rao, P. S. (2014). Rheological and structural characterization of prepared aqueous Aloe vera dispersions. Food Research International, 62, 10291037. https://doi.org/10.1016/j.foodres.2014.05.033

Kiran, P., Swami Hulle, N. R. \& Rao, P. S. (2017). Viscoelastic behavior of reconstituted Aloe vera hydrogels as a function of concentration and temperature. International Journal of Food Properties, 20(2), 475-490. https://doi.or $\mathrm{g} / 10.1080 / 10942912.2016 .1168436$

Kobayashi, Y. (2008). The role of chemokines in neutrophil biology. Frontiers in Bioscience: A Journal and Virtual Library, 13, 2400-2407. DOI: 10.2741/2853

Koga, A. Y., Pereira, A. V., Lipinski, L. C. \& Oliveira, M. R. (2018). Evaluation of wound healing effect of alginate films containin g Aloe vera (Aloe barbadensis Miller) gel. Journal of Biomaterials Applications, 32(9), 1212-1221. https://doi.org/10.1177/0885328218754615

Koh, T. J. \& DiPietro, L. A. (2011). Inflammation and wound healing: The role of the macrophage. Expert Reviews in Molecular Medicine, 13, e23 DOI: 10.1017/ S1462399411001943

Kumar, M. N. R. (2000). A review of chitin and chitosan applications. Reactive and Functional Polymers, 46(1), 1-27. https://doi.org/10.1016/S1381-5148(00)00038-9

Landén, N. X., Li, D. \& Ståhle, M. (2016). Transition from inflammation to proliferation: A critical step during wound healing. Cellular and Molecular Life Sciences, 73(20), 3861-3885.

Lee, K. Y. \& Mooney, D. J. (2012). Alginate: Properties and biomedical applications. Progress in Polymer Science, 37(1), 106-126. https://doi.org/10.1016/j. progpolymsci.2011.06.003

Li, M., Han, M., Sun, Y., Hua, Y., Chen, G. \& Zhang, L. (2019). Oligoarginine mediated collagen/chitosan gel composite for cutaneous wound healing. International Journal of Biological Macromolecules, 122, 1120-1127. https://doi.org/10.1016/j.ijbiomac.2018.09.061

Lin, H.-Y., Chen, H.-H., Chang, S.-H. \& Ni, T.-S. (2013). Pectin-chitosan-PVA nanofibrous scaffold made by electrospinning and its potential use as a skin tissue scaffold. Journal of Biomaterials Science, Polymer Edition, 24(4), 470-484. DOI: 10.1080/09205063.2012.693047 
López-Mata, M. A., García-González, G., Valbuena-Gregorio, E., Ruiz-Cruz, S., Zamudio-Flores, P. B., Burruel-Ibarra, S. E., Morales-Figueroa, G.G. \& Quihui-Cota, L. (2016). Development and characteristics of biodegradable Aloegel/egg white films. Journal of Applied Polymer Science, 133(40), 44067. DOI: 10.1002/app.44067

López-Mata, M. A., Gastelum-Cabrera, M., ValbuenaGregorio, E., Zamudio-Flores, P. B., Burruel-Ibarra, S. E., Morales-Figueroa, G. G., Quihui-Cota, L. \& JuárezOnofre, J. E. (2018). Physicochemical properties of novel pectin/Aloe gel membranes. Iranian Polymer Journal, 27, 545-553. https://doi.org/10.1007/s13726-018-0631-8

Lupton, J. R. (2000). Is fiber protective against colon cancer? Where the research is leading us. Nutrition, 16(7), 558561. DOI: 10.1016/s0899-9007(00)00350-6

Maan, A. A., Nazir, A., Khan, M. K. I., Ahmad, T., Zia, R., Murid, M. \& Abrar, M. (2018). The therapeutic properties and applications of Aloe vera: A review. Journal of Herbal Medicine, 12, 1-10. https://doi.org/10.1016/j. hermed.2018.01.002

Maenthaisong, R., Chaiyakunapruk, N., Niruntraporn, S. \& Kongkaew, C. (2007). The efficacy of Aloe vera used for burn wound healing: A systematic review. Burns, 33(6), 713-718. https://doi.org/10.1016/j.burns.2006.10.384

Mansour, G., Ouda, S., Shaker, A. \& Abdallah, H. M. (2014). Clinical efficacy of new aloe vera-and myrrh-based oral mucoadhesive gels in the management of minor recurrent aphthous stomatitis: A randomized, double-blind, vehiclecontrolled study. Journal of Oral Pathology \& Medicine, 43(6), 405-409. https://doi.org/10.1111/jop.12130

Martins, J. G., Camargo, S. E. A., Bishop, T. T., Popat, K. C., Kipper, M. J. \& Martins, A. F. (2018). Pectin-chitosan membrane scaffold imparts controlled stem cell adhesion and proliferation. Carbohydrate Polymers, 197, 47-56. https://doi.org/10.1016/j.carbpol.2018.05.062

Meyer, C., Stenberg, L., Gonzalez-Perez, F., Wrobel, S., Ronchi, G., Udina, E., Suganuna, S., Geuna, S, Navarro, X., Dahlin, L. B., Grothe, C. \& Haastert-Talini, K. (2016). Chitosan-film enhanced chitosan nerve guides for long-distance regeneration of peripheral nerves. Biomaterials, 76, 33-51. https://doi.org/10.1016/j. biomaterials.2015.10.040

Miguel, S. P., Moreira, A. F. \& Correia, I. J. (2019). Chitosan based-asymmetric membranes for wound healing: A review. International Journal of Biological Macromolecules. 127, 460-475. https://doi.org/10. 1016/j.ijbiomac.2019.01.072

Mir, M., Ali, M. N., Barakullah, A., Gulzar, A., Arshad, M., Fatima, S. \& Asad, M. (2018). Synthetic polymeric biomaterials for wound healing: A review. Progress in Biomaterials, 7(1), 1-21. DOI: 10.1007/s40204-0180083-4

Montón Echeverría, J., Pérez Redondo, S. \& Gómez Bajo, G. J. (2007). Experiencia clínica en el empleo de factores de crecimiento autólogos obtenidos de plasma rico en plaquetas. Cirugía Plástica Ibero-Latinoamericana, 33(3), 155-162.

Moon, E.-J., Lee, Y. M., Lee, O.-H., Lee, M.-J., Lee, S.-K., Chung, M.-H., Park, Y-I, Sung, C-K., Choi, J-S. \& Kim, K.-W. (1999). A ncovel angiogenic factor derived from Aloe vera gel: $\beta$-sitosterol, a plant sterol. Angiogenesis, 3(2), 117-123. https://doi.org/10.1023/A:1009058232389

Moura, L. I. F., Dias, A. M. A., Carvalho, E. \& Sousa, H. C. de. (2013). Recent advances on the development of wound dressings for diabetic foot ulcer treatment-A review. Acta Biomaterialia, 9(7), 7093-7114. https://doi. org/10.1016/j.actbio.2013.03.033

Oryan, A., Mohammadalipour, A., Moshiri, A. \& Tabandeh, M. R. (2016). Topical application of Aloe vera accelerated wound healing, modeling, and remodeling: An experimental study. Annals of Plastic Surgery, 77(1), 37-46. DOI: 10.1097/SAP.0000000000000239

Park, S.-B., Lih, E., Park, K.-S., Joung, Y. K. \& Han, D. K. (2017). Biopolymer-based functional composites for medical applications. Progress in Polymer Science, 68, 77-105. DOI: 10.1016/j.progpolymsci.2016.12.003

Patrulea, V., Ostafe, V., Borchard, G. \& Jordan, O. (2015). Chitosan as a starting material for wound healing applications. https://doi.org/10.1016/j.ejpb.2015.08.004

Penn, J. W., Grobbelaar, A. O. \& Rolfe, K. J. (2012). The role of the TGF- $\beta$ family in wound healing, burns and scarring: A review. International Journal of Burns and Trauma, 2(1), 18-28.

Pereira, G. G., Santos-Oliveira, R., Albernaz, M. S., Canema, D., Weismüller, G., Barros, E. B., Magalhaes, L., LimaRibeiro, M. H. M., Pohlmann, A. R. \& Guterres, S. S. (2014). Microparticles of Aloe vera/vitamin E/chitosan: Microscopic, a nuclear imaging and an in vivo test analysis for burn treatment. European Journal of Pharmaceutics and Biopharmaceutics, 86(2), 292-300. https://doi. org/10.1016/j.ejpb.2013.10.011

Pereira, R., Carvalho, A., Vaz, D. C., Gil, M. H., Mendes, A. \& Bártolo, P. (2013). Development of novel alginate based hydrogel films for wound healing applications. International Journal of Biological Macromolecules, 52, 221-230. DOI: 10.1016/j.ijbiomac.2012.09.031

Pereira, R. F., Carvalho, A., Gil, M. H., Mendes, A. \& Bártolo, P. J. (2013). Influence of Aloe vera on water absorption and enzymatic in vitro degradation of alginate hydrogel films. Carbohydrate Polymers, 98(1), 311-320. https:// doi.org/10.1016/j.carbpol.2013.05.076

Ray, A. \& Aswatha, S. M. (2013). An analysis of the influence of growth periods on physical appearance, and acemannan and elemental distribution of Aloe vera L. gel. Industrial Crops and Products, 48, 36-42. https://doi.org/10.1016/j. indcrop.2013.03.024

Reynolds, T \& Dweck, A. C. (1999). Aloe vera leaf gel: A review update. Journal of Ethnopharmacology, 68(1-3), 
3-37. https://doi.org/10.1016/S0378-8741(99)00085-9

Ridiandries, A., Tan, J. T. M. \& Bursill, C. A. (2018). The Role of Chemokines in Wound Healing. International Journal of Molecular Sciences, 19(10), 3217. DOI: 10.3390/ijms19103217

Schweizer, M. (1995). Aloe vera: La planta que cura. Apophtegme, Francia. Recuperado de http://www. aloesencial.com/aloesp.pdf

Serra, M. B., Barroso, W. A., Silva, N. N. da, Silva, S. do N., Borges, A. C. R., Abreu, I. C. \& Borges, M. O. da R. (2017). From Inflammation to Current and Alternative Therapies Involved in Wound Healing. International Journal of Inflammation, 2017, ID 3406215. DOI: $10.1155 / 2017 / 3406215$

Shah, S. A., Sohail, M., Khan, S., Minhas, M. U., Matas, M. de, Sikstone, V., Hussain, Z., Abbasi, M. \& Kousar, M. (2019). Biopolymer-based biomaterials for accelerated diabetic wound healing: A critical review. International Journal of Biological Macromolecules, 139, 975-993. https://doi.org/10.1016/j.ijbiomac.2019.08.007

Silva, S. S., Caridade, S. G., Mano, J. F. \& Reis, R. L. (2013). Effect of crosslinking in chitosan Aloe verabased membranes for biomedical applications. Carbohydrate Polymers, 98(1), 581-588. DOI: 10.1016/j. carbpol.2013.06.022

Silva, S. S., Popa, E. G., Gomes, M. E., Cerqueira, M., Marques, A. P., Caridade, S. G., Teixeira, P., Sousa, C. Mano, J. F. \& Reis, R. L. (2013). An investigation of the potential application of chitosan/Aloe-based membranes for regenerative medicine. Acta Biomaterialia, 9(6), 6790-6797. DOI: 10.1016/j.actbio.2013.02.027

Singh, S., Gupta, A. \& Gupta, B. (2018). Scar free healing mediated by the release of Aloe vera and manuka honey from dextran bionanocomposite wound dressings. International Journal of Biological Macromolecules, 120, 1581-1590. https://doi.org/10.1016/j. ijbiomac.2018.09.124

Sinno, H. \& Prakash, S. (2013). Complements and the Wound Healing Cascade: An Updated Review. Plastic Surgery International, 2013, ID 146764. DOI: $10.1155 / 2013 / 146764$

Sionkowska, A. (2011). Current research on the blends of natural and synthetic polymers as new biomaterials: Review. Progress in Polymer Science, 36(9), 1254-1276. https://doi.org/10.1016/j.progpolymsci.2011.05.003

Sriamornsak, P. (2003). Chemistry of pectin and its pharmaceutical uses: A review. Silpakorn University International Journal, 3(1-2), 206-228.

Sullivan, D. J., Cruz-Romero, M., Collins, T., Cummins, E., Kerry, J. P. \& Morris, M. A. (2018). Synthesis of monodisperse chitosan nanoparticles. Food Hydrocolloids, 83, 355-364. https://doi.org/10.1016/j. foodhyd.2018.05.010

Surjushe, A., Vasani, R. \& Saple, D. G. (2008). Aloe vera: A short review. Indian Journal of Dermatology, 53(4), 163166. DOI: 10.4103/0019-5154.44785

Takagi, N., Kawakami, K., Kanno, E., Tanno, H., Takeda, A., Ishii, K., Imai, Y., Iwakura, Y. \& Tachi, M. (2017). IL-17A promotes neutrophilic inflammation and disturbs acute wound healing in skin. Experimental dermatology, 26(2), 137-144. https://doi.org/10.1111/exd.13115

Tan, P. Y., Tan, T. B., Chang, H. W., Tey, B. T., Chan, E. S., Lai, O. M., Baharin, B. S., Nehdi, I. A. \& Tan, C. P. (2018). Effects of storage and yogurt matrix on the stability of tocotrienols encapsulated in chitosan-alginate microcapsules. Food Chemistry, 241, 79-85. https://doi. org/10.1016/j.foodchem.2017.08.075

Tchemtchoua, V. T., Atanasova, G., Aqil, A., Filée, P., Garbacki, N., Vanhooteghem, O., Deroanne, C., Noel, A., Jérome, C., Nusgens, B., Poumay, Y. \& Colige, A. (2011). Development of a Chitosan Nanofibrillar Scaffold for Skin Repair and Regeneration. Biomacromolecules, 12(9), 3194-3204. DOI: 10.1021/bm200680q

Tummalapalli, M., Berthet, M., Verrier, B., Deopura, B. L., Alam, M. S. \& Gupta, B. (2016). Composite wound dressings of pectin and gelatin with Aloe vera and curcumin as bioactive agents. International Journal of Biological Macromolecules, 82(Supplement C), 104113. DOI: 10.1016/j.ijbiomac.2015.10.087

Vargas-Ruiz, Á. G. (2016). El fibrinógeno: Su fisiología e interacciones en el sistema de la coagulación. Revista Mexicana de Anestesiología, 39(S2), 321-323.

Vega, A., Ampuero, N., Díaz, L. \& Lemus, R. (2005). El Aloe vera (Aloe barbadensis Miller) como componente de alimentos funcionales. Revista Chilena de Nutrición, 32(3), 208-214. http://dx.doi.org/10.4067/S071775182005000300005

Venkatesan, J., Bhatnagar, I., Manivasagan, P., Kang, K.H. \& Kim, S.-K. (2015). Alginate composites for bone tissue engineering: A review. International Journal of Biological Macromolecules, 72, 269-281. https://doi. org/10.1016/j.ijbiomac.2014.07.008

Vinson, J. A., Al Kharrat, H. \& Andreoli, L. (2005). Effect of Aloe vera preparations on the human bioavailability of vitamins C and E. Phytomedicine, 12(10), 760-765. https://doi.org/10.1016/j.phymed.2003.12.013

Voragen, A. G. J., Coenen, G.-J., Verhoef, R. P. \& Schols, H. A. (2009). Pectin, a versatile polysaccharide present in plant cell walls. Structural Chemistry, 20(2), 263. DOI: 10.1007/s11224-009-9442-z

Zapata, P. J., Navarro, D., Guillén, F., Castillo, S., MartínezRomero, D., Valero, D. \& Serrano, M. (2013). Characterisation of gels from different Aloe spp. As antifungal treatment: Potential crops for industrial applications. Industrial Crops and Products, 42, 223-230. https://doi.org/10.1016/j.indcrop.2012.06.002 